\title{
BMJ Open Perspective of asylum-seeking caregivers on the quality of care provided by a Swiss paediatric hospital: a qualitative study
}

\author{
Julia Brandenberger, ${ }^{\oplus 1,2}$ Katrin Sontag, ${ }^{3}$ Cédric Duchêne-Lacroix, ${ }^{4}$ \\ Fabienne Nicole Jaeger, ${ }^{5}$ Bernadette Peterhans, ${ }^{5}$ Nicole Ritz ${ }^{\circ}$
}

To cite: Brandenberger J, Sontag K, Duchêne-Lacroix C, et al. Perspective of asylumseeking caregivers on the quality of care provided by a Swiss paediatric hospital: a qualitative study. BMJ Open 2019;9:e029385. doi:10.1136/ bmjopen-2019-029385

- Prepublication history and additional material for this paper are available online. To view please visit the journal (http:// dx.doi.org/10.1136/bmjopen2019-029385).

Received 29 January 2019 Revised 01 July 2019 Accepted 05 July 2019

\section{Check for updates}

(c) Author(s) (or their employer(s)) 2019. Re-use permitted under CC BY-NC. No commercial re-use. See rights and permissions. Published by BMJ.

${ }^{1}$ Migrant Health Services, Universitats-Kinderspital beider Basel (UKBB), Basel, Switzerland ${ }^{2}$ Department of Pediatric Emergency Medicine, Inselspital Universitatsspital Bern, Bern,

Switzerland

${ }^{3}$ Department of Social

Sciences, Subject Area Cultural Anthropology, University of Basel, Basel, Switzerland

${ }^{4}$ Department of Social Sciences, University of Basel, Basel,

Switzerland

${ }^{5}$ Professional Postgraduate

Training Unit, Swiss Tropical and

Public Health Institute, Basel,

Switzerland

Correspondence to

Dr Nicole Ritz;

nicole.ritz@unibas.ch

\section{ABSTRACT}

Objectives This study investigated the perspective of asylum-seeking caregivers on the quality of healthcare delivered to their children in a qualitative in-depth interview study. The health of asylum-seeking children is of key interest for healthcare providers, yet knowledge of the perspective of asylum-seeking caregivers when accessing healthcare is limited.

Setting The study took place in a paediatric tertiary care hospital in Basel, Switzerland.

Participants Interviews were done with 13 asylumseeking caregivers who had presented with their children at the paediatric tertiary care hospital. Nine female and four male caregivers from Tibet, Eritrea, Afghanistan, Syria, Iraq, Albania and Macedonia were included. A diverse sample was chosen regarding cultural and social background, years of residence in Switzerland and reasons for seeking care. A previously developed and pilot-tested interview guide was used for semistructured in-depth interviews between 36 and 92 min in duration. Data analysis and reporting was done according to Consolidated Criteria for Reporting Qualitative Research. The number of interviews was determined by saturation of data. Results The interviewees described a mismatch of personal competencies and external challenges. Communication barriers and unfamiliarity with new health concepts were reported as challenges. These were aggravated by isolation and concerns about their child's health. The following factors were reported to strongly contribute to satisfaction of healthcare delivery: a respectfu and trusting caregiver-provider relationship, the presence of interpreters and immediate availability of treatment. Conclusions A mismatch of personal competencies and external challenges importantly influences the caregiverprovider relationship. To overcome this mismatch establishment of confidence was identified as a key factor. This can be achieved by availability of interpreter services, sufficient consultation time and transcultural trainings for healthcare workers. Coordination between the family, the government's asylum system and the medical system is required to facilitate this process.

\section{BACKGROUND}

The recent increase of the global refugee population to 22.5 million people is the
Strengths and limitations of this study

- The inclusion of a cross-language concept and theoretical background.

- A thoroughly validated interview guide.

- A rigorous analysis, supported by an interdisciplinary research team.

- As in-depth qualitative study, this study comprises a relatively small sample.

- Due to the heterogeneity of the study population minor, culturally specific aspects might not have been sufficiently covered.

highest level ever recorded and poses challenges to healthcare systems and public health of host countries. ${ }^{1}$ In 2017, European countries recorded 209756 asylum claims by children. ${ }^{2}$ Despite decreasing overall numbers of refugees arriving in Europe, national asylum services still registered over 115000 asylum applications by children from January to September 2018. ${ }^{3}$ In Switzerland over 45000 asylum applications were registered in 2016 and 2017. ${ }^{4}$ The age of asylum seekers has dramatically decreased in the last decade with $82 \%$ of asylum seekers in Europe being aged below 35 years and approximately one-third being children and adolescents below 18 years of age in $2017 .^{5}$

Many refugees have had limited access to healthcare for years and therefore arrive in host countries with neglected health conditions. ${ }^{6-8}$ The health of asylum-seeking children and adolescents is of key interest, as these represent an increasing refugee population in recent years and are a particularly vulnerable group. ${ }^{9-11}$

Access to quality healthcare for asylum seekers and refugees remains challenging and it is critical to identify underlying reasons. ${ }^{12} 13$ This needs to be done from the perspective of healthcare providers as well as 
patients and their caregivers alike as the perception of challenges and expectations on quality of care provided may vary substantially. ${ }^{1415}$

Current understanding and evidence regarding challenges for the healthcare provision to asylum seekers and refugees is growing. A recent systematic review focused on qualitative studies investigating challenges and facilitators in providing healthcare to asylum seekers and refugees. It identified three main fields influencing healthcare: the asylum process, the healthcare system and the healthcare encounter. ${ }^{16}$ An important limitation of the review is that all included studies reported on the providers' perspective. ${ }^{16} \mathrm{~A}$ recent review by our group on challenges in healthcare delivery to asylum seekers and refugees in high-income countries included several studies assessing the asylum-seeking patients' perspective ${ }^{17-28}$ and identified financial, legal, geographical and cultural challenges as additional external factors influencing access to healthcare. ${ }^{29}$

Very few studies have explored the perspectives of migrant caregivers and, to date, there have been no studies performed exclusively including asylum-seeking and refugee caregivers. Two Australian studies investigated their perspective on the quality of antenatal and early child healthcare. ${ }^{24} 28$ One study from the USA focused on health beliefs of migrant parents, working on farms ${ }^{23}$ and one European study investigated migrant caregivers' perception on how to maintain their children's health. ${ }^{30}$ Therefore, studies assessing the perspective of asylum-seeking and refugee caregivers on quality of care provided to their children beyond the neonatal period and in the European context are lacking. To reduce this important knowledge gap, the aim of our study was to explore the perspective of asylum-seeking caregivers on the quality of care provided in a Swiss paediatric hospital.

\section{METHODS}

\section{Study design and setting}

The study was designed as qualitative in-depth interview study at the University Children's Hospital Basel. The hospital is located in the city of Basel, which hosts the largest reception centre for asylum seekers in the area of Northwest Switzerland, where asylum seekers are accommodated immediately after arrival for a maximum of 3 months. ${ }^{31}$ The city of Basel also has various accommodations for accepted refugees and those in a prolonged asylum-seeking evaluation process. The hospital receives referrals for children from the asylum reception centre and the various regional accommodations and asylum centres.

\section{Study population}

Caregivers of asylum-seeking children who presented to our hospital on working days were eligible for inclusion. We aimed to include a heterogeneous group of caretakers and performed purposive sampling using the following criteria to cover different perspectives: (A) recent and distant (>2 years) arrival in Switzerland; (B) first and regular attendance to the hospital; (C) presentation at the emergency department and at outpatient clinics; and (D) origin from different regions.

Potential participants were approached by the interviewer supported by a phone interpreter. Following oral consent, a separate appointment was scheduled with a face-to-face interpreter. Study participants' preference regarding language, dialect and gender of the interpreter was followed.

\section{Sample size}

Sample size determination was based on recommendations by the National Centre for Research Methods in the $\mathrm{UK}^{32}$ We aimed to achieve data saturation, expecting to include12 interviews until new data would mainly repeat information that was collected in previous interviews. ${ }^{33}$ Saturation of the study results was discussed and determined by the interdisciplinary study team.

\section{Data collection}

A semistructured interview guide (table 1 and online supplementary data 1) was designed consisting of open questions mandatorily to be covered, followed by prompts to clarify given answers and allow for exploration of emerging, not previously specified topics. ${ }^{34}$

The interview guide was reviewed by an external organisational psychologist with extensive experience in qualitative research. After external revision two pilot interviews were performed to test intelligibility, acceptability and extensiveness. A further revision was done based on feedback from the caregivers involved in the pilot interviews. To address the challenges in cross-language qualitative research ${ }^{35-37}$ and minimise the language barrier, a cross-language concept was developed, describing steps of translation and quality control (figure 1). The cross-language concept was developed using the guidelines on interpreter use of the Qualitative Forum of Social Science. ${ }^{38}$

Baseline data were collected using a case report form (online supplementary data 2). The in-depth interviews were done according to participants' preference at their home, asylum residence or at the hospital. Interview duration was scheduled for $60 \mathrm{~min}$ and done once only. All interviews were audiotaped and transcribed as pure verbatim protocols ${ }^{39}$ in either English or German with anonymisation of all patients. The transcriptions were reviewed in detail by the interpreter present during the interview according to the cross-language concept. Paraverbal reactions, interactions between family members, other observations and cultural aspects were documented in field notes and discussed by the interviewer and interpreter during debriefing.

\section{The role of the interviewer}

The interviewer (JB) is an experienced female clinician-scientist (MD) and conducted all pilot and study interviews. During the study period she was employed by 
Table 1 Interview guideline-practical design (translated version)

\begin{tabular}{l} 
Open mandatory question \\
\hline Introduction \\
Think about the moment \\
before you came to the \\
hospital - what made you \\
come?
\end{tabular}

Prompts level I (specification)

Prompts level II (additional specification)

Interview done as conversation

Present role of interviewer, confidentiality

Duration of maximum 1 hour

Consent for audio recording

Everything which you mention is important and

correct

Answers will be summarised together with those of other parents

Who referred you to the hospital?

What was the reason for presentation?

How was the child/your situation before you

What information was given to you?

How was the communication?

Can you comment on waiting times?

Were there any uncertainties?

came?

Has anyone done the registration for you or did you do it yourself?

Is this your first time at the children's hospital?

Were you referred?

Did you know what you needed to do?

(Information given by staff)

Why did you come that day, what illness did your child have?

What was helpful when you arrived and were there situations where you needed more support? How did the staff communicate with you? How did you communicate with the staff? Were there moments when you were not sure what to do?

\begin{tabular}{|c|c|c|}
\hline $\begin{array}{l}\text { Tell us what happened } \\
\text { when you arrived at the } \\
\text { hospital. }\end{array}$ & $\begin{array}{l}\text { You arrived at the reception and what } \\
\text { happened next? } \\
\text { Did you have accompanying persons? } \\
\text { Did you feel understood in your concerns? } \\
\text { Did you see a doctor a nurse first? } \\
\text { Did you think that what the staff did with your } \\
\text { child was right? } \\
\text { How did you feel? }\end{array}$ & $\begin{array}{l}\text { You presented to the reception / registration at } \\
\text { the hospital and then? } \\
\text { Was someone there? } \\
\text { Did you know how to proceed? How were waiting } \\
\text { times? Did you get any information? } \\
\text { Was an interpreter present for your consultation? } \\
\text { Was this the first time you presented to the } \\
\text { hospital? } \\
\text { Did you need similar medical treatment before? } \\
\text { What was helpful when presenting to the } \\
\text { hospital? } \\
\text { Where do you think more support is/was } \\
\text { needed? } \\
\text { Did the staff understand you and your concerns? } \\
\text { What happened next? Tell me about the doctor } \\
\text { and the care provided. } \\
\text { Did you understand her/him? Was there an } \\
\text { interpreter required/ organised? } \\
\text { Did you trust the staff, that what they did with } \\
\text { your child was right? } \\
\text { Did you feel safe at home? }\end{array}$ \\
\hline
\end{tabular}

Continued 
Table 1 Continued

Open mandatory question

How was the care your child received?
Prompts level I (specification)

Was the care as intended/expected?

What is different compared to your country of origin?

Would you come back to this hospital for treatment?

Prompts level II (additional specification)

Was the care as you thought it would be?

Were there situations where you thought it should be different or faster?

Did you trust the doctors / other medical staff at the hospital? How did you feel? (sad, insecure, angry)

What was particularly well done? What did you tell your friends? Concrete un/helpful behaviour of health care workers? What would have been different in your country of origin? What would you like to introduce here from your country of origin? What would you like to introduce in your country of origin from here? What role does religion play in the hospital for you? Would you return to the hospital, recommend it to your compatriots? If you came back to the hospital, what would you like to be different? What should remain the same? Can you describe what characterises the perfect doctor/nurse for you?

$\begin{array}{ll}\text { What was your general } & \text { Were any drugs given to your child? } \\ \text { impression? } & \text { Did you receive further instructions on } \\ \text { treatment from the doctor? } & \text { Do you think that what the doctor suggested } \\ \text { helped? If not, why? } \\ \text { Are further appointments planned? } \\ \text { Does your child have a paediatrician outside } \\ \text { the hospital? } \\ \text { Do you know where to go for health issues? }\end{array}$

What medication did your child receive? Did you get a prescription? Did you get instructions on how to give the medication to your child? How/Where did you get the medication?

Did you follow the doctor's instructions or did you do it differently?

Did you have a contact person in case of uncertainty and questions after the hospital consultation? Are more doctor visits planned? Does your child have a paediatrician? If not, why not? If so, how did you find her/him?

Wrap up
Do you have further things to add? Was it easy to express your opinion? Give phone number from interviewer for inquiries arising from today's discussion.

From my point of view, we have addressed all topics. Many thanks for your valuable thoughts and discussion points.

Are there any additions from your point of view? How do you feel after the conversation? Do you have more questions?

How could we best ask the opinion of your compatriots? How do you ask for feedback in your country?

What else can we help you with?

\begin{tabular}{|c|c|c|}
\hline Context & $\begin{array}{l}\text { Where were you born? } \\
\text { How did you come to Switzerland? }\end{array}$ & $\begin{array}{l}\text { If you were not born in Switzerland, where have } \\
\text { you lived previously? } \\
\text { Do you have previous experiences with } \\
\text { hospitals? }\end{array}$ \\
\hline
\end{tabular}

UKBB, Universitats-Kinderspital beider Basel.

the University Children's Hospital Basel in the migrant health service research group. She is experienced in qualitative research, received trainings in interview techniques and qualitative research methods and has a special interest in global health. Not knowing JB beforehand, the interviewer's background, the purpose and goals of the 


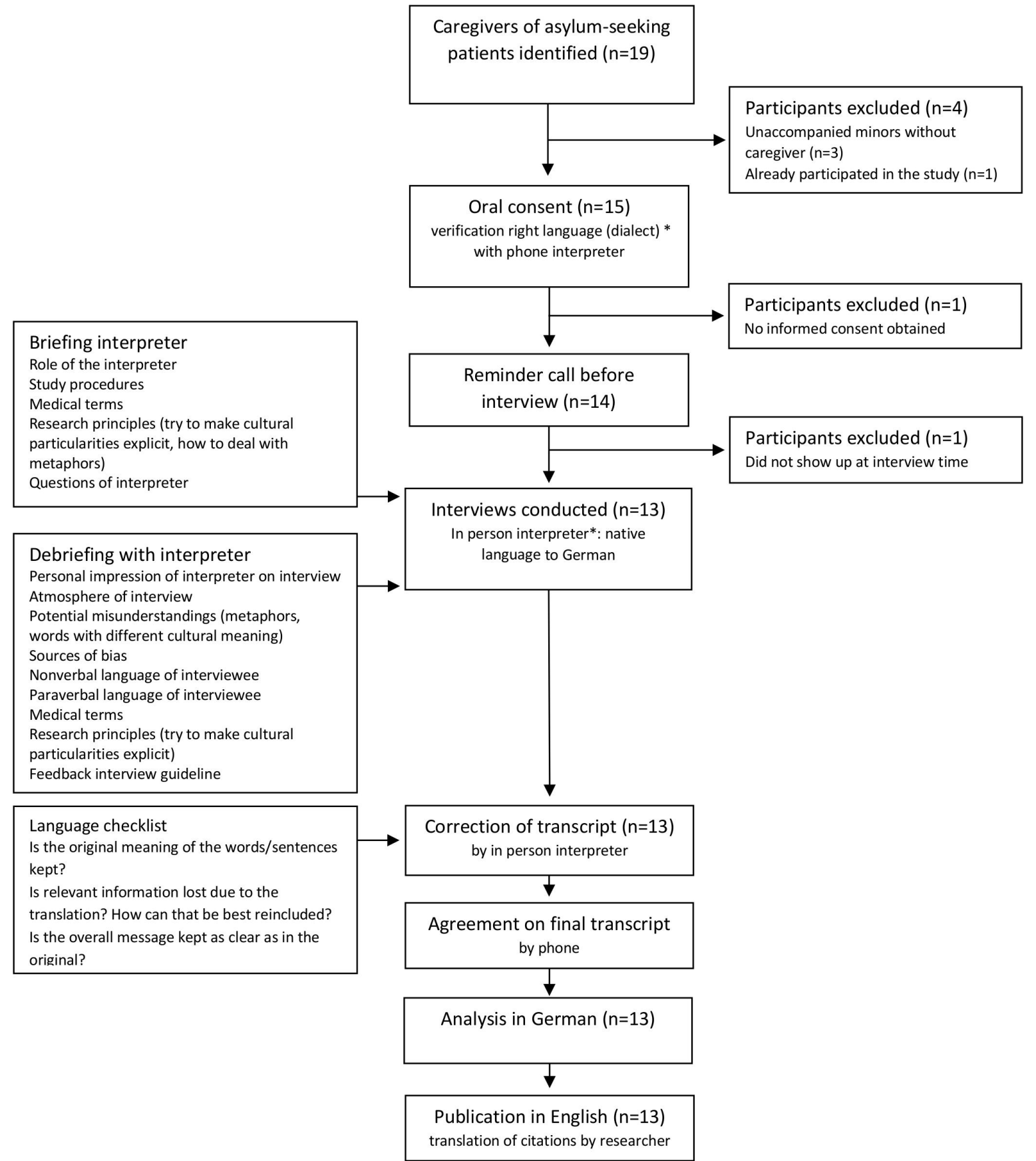

Figure 1 Flow chart depicting the different phases of the patient recruitment and the cross-language concept including transcription, translation and understanding of language. ${ }^{\star}$ If communication in German/English not adequate.

study were explained to the participants during the oral consent and repeated during the introduction phase of the interview.

\section{Data analysis and reporting}

Data analysis was done according to the qualitative content analysis of Mayring. ${ }^{39}$ A codebook (online supplementary data 3) was prepared and refined in several steps, involving team discussion with JB, KS and CDL. Four interviews were coded in parallel by each researcher to ensure the comprehensiveness of the codebook. Code categories were extracted, relations identified and abstracted in networks and graphs to generate a coding tree. Reporting was guided by the Consolidated Criteria for Reporting Qualitative Research (online supplementary data 4).$^{40}$ The analysis was done using atlas.ti (ATLAS. ti 8 Scientific Software Development, Berlin). The entire study process was accompanied by the interdisciplinary Migration Research Group at the University of Basel.

\section{Patient and public involvement}

During pilot interviews caregivers' feedback was obtained to improve the interview guide and the way the interviews were done. After the pilot phase all participants were asked if the method was suitable and how they felt about expressing their opinion at the end of the interview. An 
interim expert panel discussion consisting of staff from the asylum-seeking reception centre and the University Children's Hospital Basel was organised to evaluate results. In addition, one interview participant reviewed the entire paper.

\section{Ethics}

As a quality assessment project of the University Children's Hospital Basel, there was no ethical approval required for this study. This was confirmed by the Ethics Committee of Northwest/Central Switzerland on 4 October 2017. We strictly adhered to international research standards rigorously including information about entirely voluntary participation of the interviewees and the possibility to withdraw consent without any negative consequences, separation of research and clinical staff and data confidentiality.

\section{RESULTS}

A total of 13 interviews were performed and included in the analysis, conducted in Tigrinya, English, Arabic, Dari, Farsi and German (figure 1). In all interviews, the professional interpreters ensured a smooth dialogue between the participant and the interviewer and helped establish a pleasant atmosphere. The baseline characteristics of participating caregivers and the interview context are summarised in table 2. Caregivers are quoted in the text using the format: $\mathrm{x} ; \mathrm{yy}: \mathrm{zz}$. $\mathrm{X}$ is the interview number, yy the paragraph number and $\mathrm{zz}$ the line number.

\section{Mismatch of competences and organisational challenges}

Caregivers described mismatches between their personal, sociocultural and language competencies and the situation of healthcare. In addition, they faced organisational challenges, for example, orientation to new surroundings after relocations. They described that this created stressful situations leading to feelings of disorientation, dependency and anxiety. This was felt strongest early after arrival and for those who had not previously lived in a cultural context like Switzerland. It became more pronounced if there was an urgent threat such as the illness of their child.

I was frightened. I didn't know the language, I didn't know anybody. I took care of my children and I didn't know where I was. [...] I was extremely worried about [my sick child]. And I didn't know: what happens? Whom should I ask? Where should I go? I had no money with me. In fact, I didn't know where I was. $(4 ; 2: 21)$

Caregivers who were unable to speak or understand a local language described communication as a challenge. The inability to sufficiently explain the medical history and complaints of their child was reported to be frustrating. Being highly dependent on interpreters, one caregiver recalled feelings of fear when the interpreter was late for the appointment.

At my second visit I was a bit frightened as the interpreter was not there. I thought: oh my God: how can
I understand now [what they say]? How can I talk to them? I was a bit nervous in this moment, this was a bit difficult. $(13 ; 14: 31)$

\section{Mismatch of health concepts}

Caregivers explained that their own health concepts were shaped by their culture and previous experiences. They arrived with certain expectations about Swiss healthcare based on stories they had heard. One important topic was the use of medication. Two caregivers stated that they had wished to receive a prescription for medication.

In Afghanistan [...] doctors have limited resources. We don't have many options. But if you go to the doctor $[\ldots]$ you get medication and you get antibiotics if you have an inflammation or something like that. Here, that's not the case. You continue to be sick, after four or five consultations it gets better, yes, but maybe it would have been better anyway. ( $3 ; 29: 46)$

In Syria, when my son or my daughter was sick, I just went to the pharmacy. It's like a supermarket. And then I buy $[\ldots]$ antibiotics too, that's completely normal. $(10 ; 7: 24)$

Some health concepts such as preventive services were reported to be unfamiliar. For one caregiver the detailed examination of the child during tuberculosis screening suggested to her that the child was seriously sick. The caregiver was unable to imagine why this was required when no obvious health problem was present. She explained that the idea of going to the hospital with an apparently healthy child was completely new to her.

I knew my children were not having tuberculosis. However, I was frightened. Because they work so thoroughly [at the hospital] and they have done examinations, and that is why I was really frightened. $(7 ; 4: 40)$

For some caregivers, the way in which physicians would communicate about health was unfamiliar. One caregiver mentioned that bad news was disclosed to her by five physicians which was a shocking and unpleasant experience. In addition, the information was given faster and much more directly than she was used to. She had wished that only one person had given here the information in small steps. Other caregivers, too, wished that physicians would explain more about the disease, causes and resulting treatment.

\section{Limited personal resources}

For caregivers being part of a family was considered a resource and being separated from loved ones was a psychological challenge. In many instances mothers described arriving in Switzerland with their children but without their husbands. They were reported to have been forced to stay as soldiers or prisoners or had been killed before the family left. In case of limited financial resources, priority was given to the mother and children leaving the country. The lack of communication with them or other family members was contributing to the feeling of loneliness. This 


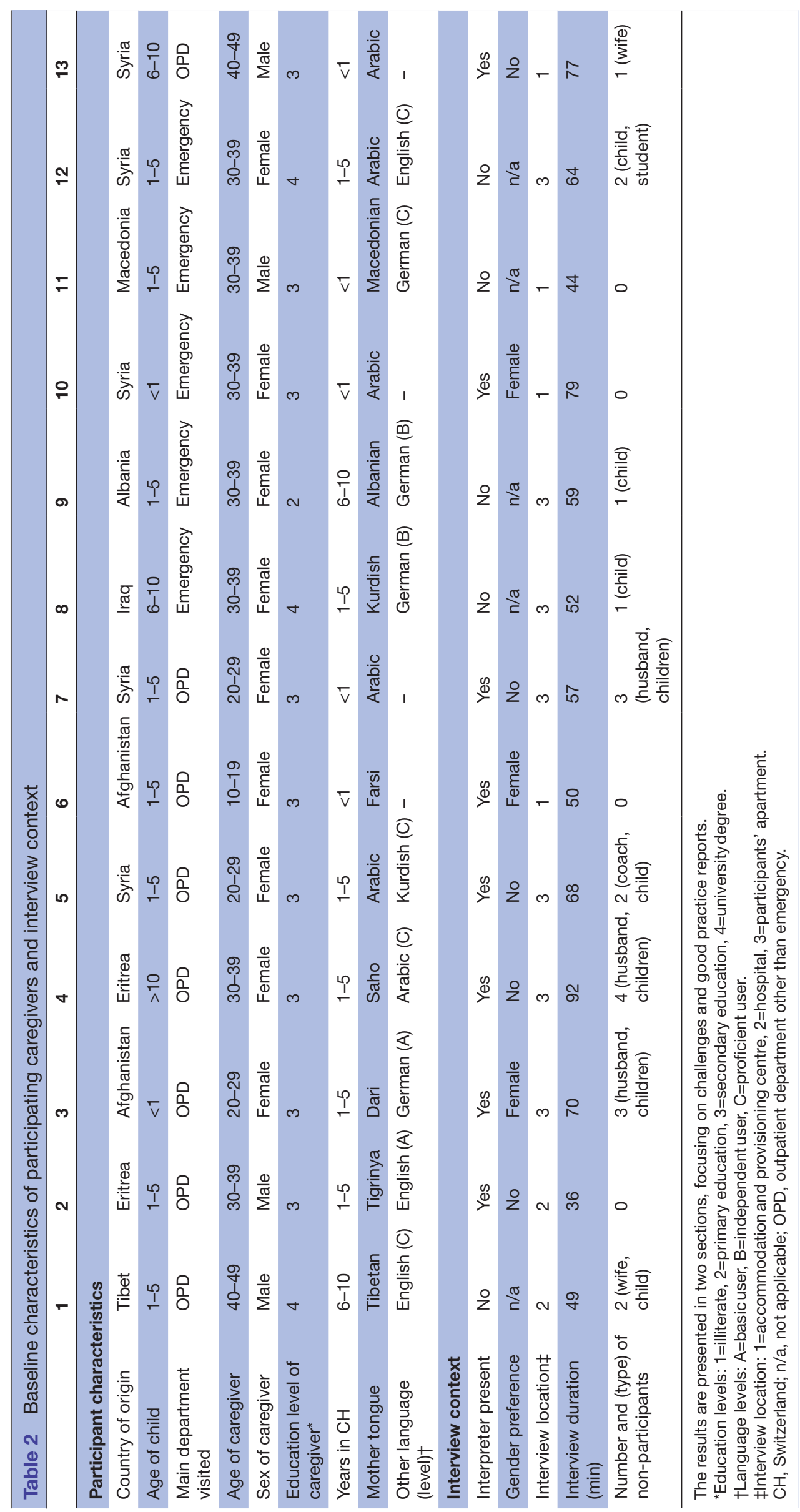


was aggravated if a child was diagnosed with serious health problems and had to be admitted to the hospital.

I had no clue about a health insurance, no clue about the law, the law here and the rules. I just endured these days there [on the ward]. [...] I felt very lonely. My husband was not here at that time. That was very difficult. $(3 ; 29: 16)$

Being a single caregiver had practical implications. For example, attendance to medical appointments was challenging as childcare for healthy siblings is usually not available for asylum-seeking families. Another example was that the caregiver refused admission as she was unable to stay with her sick child.

[The doctor] said you have to stay 7 to 10 days here with your son. That's what he told me just like this. And then I answered: I can't, I have [six] children and their father is not here. $(4 ; 2: 11)$

Caregivers described how family members residing in neighbouring countries could have been of psychological and practical support. However, as their asylum process was pending, they were not allowed to cross borders. One caregiver reported crossing the border to see family members for support in a desperate situation and being caught by police.

One caregiver reported being the single parent present made it difficult to give her child the prescribed medication. When she reported this to the physician she was treated disrespectfully and asked to leave.

That's what made me angry: we told the truth to him. We can't just lie [...]. Maybe the medication doesn't taste good, doesn't smell good. I thought: [...] if I tell it to him we could maybe change it. But he was angry and just left. He said: go home! So I went home. (5; 13:32)

\section{External challenges}

Caregivers also expressed difficulty accessing healthcare, particularly if the asylum process was prolonged. In stations with pending asylum decision some participants reported that a health insurance card was not issued, which caused delays, additional administrative work and made caregivers feel inferior.

One caregiver described that the official person in charge brought the sick child to the hospital in a private car, took care of the administrative tasks and stayed with the family during the consultation. Another caregiver reported that the official person in charge was reluctant to address the family's health needs.

Three years here. My chief [official in charge] said that I'm only parked here. But I'm not a car! We are parked here, 7 years by now! With F status [provisionally admitted refugees]. Tell me, why does it have to be like that? Parked! $(9 ; 6: 98)$
Caregivers also described insufficient coordination between the asylum reception centres and the hospital. Two recently arrived mothers of admitted children did not have cash money. Unfamiliar with the system that they must buy their own food and unable to communicate that they had no money, the mothers fasted during several days or were eating from their children's meals.

Some caregivers explained that after the consultation they did not know how to return to their asylum centre/ home centre. One caregiver had recently moved and did not recall her new address. Others reported to have been driven home by the interpreter or a taxi. One caregiver living in a rural area was worried not to be able to get home and therefore left the emergency department before the end of the consultation.

\section{Understanding and responding to medical needs}

Twelve out of 13 caregivers expressed a deep gratitude for the healthcare their child received at the hospital. They also appreciated when help was offered in various situations by interpreters, officials in charge of the asylum process, taxi drivers, engaged citizens, receptionists, social workers, nurses or doctors.

It is impossible to describe, I can't describe it. Doctors or social workers, everybody supported and helped me. $(4 ; 2: 86)$

Caregivers appreciated the fact that an interpreter was used, and this led to trust as they felt understood in their most urgent need.

I swear, if I can talk there, I have the feeling that I'm safe! $(5 ; 13: 58)$

All but one caregiver explained that they were impressed by the medical help their child received. They mentioned that in the past, they never experienced such a high level of medical care, neither at their home nor in transit countries.

I don't think you see this facility in any other country.

It was around half past 10 at night. We thought he swallowed something. [...] We got really scared. [...] The doctor said: he will call the lady who is doing the $\mathrm{X}$-ray, from home. Wonderful! This is service to the King! She came from her home to do X-ray to our son. This is fascinating! $(1 ; 12: 31)$

When asked why they were satisfied with the quality of care, they emphasised the immediateness of medical care. They were used to long waiting hours extending up to days. Understanding and rapidly addressing the child's health needs lead to trust and the feeling of being understood and safe.

I like the support. The quick treatment, everything included. Not like at home, really. [...] I'm so thankful, that the child is in good hands. $(11 ; 8: 54)$

Access to good quality healthcare was for some caregivers one important reason why they lodged an asylum application in Switzerland. 
Sometimes I get nervous, I say: I'm dead, I have to leave. [...] But then I think: I have to be thankful. I have a room and my child gets an immediate checkup if he is sick. $(9 ; 6: 91)$

\section{Showing respect}

Almost all caregivers greatly appreciated that they were treated in a respectful way. Respect was even more important, if they had had negative experiences with healthcare providers in the past.

In Iran, they don't treat [...] people from Afghanistan with respect. [...] It is not like here. For example, at the reception: maybe they don't even give you a registration code, they don't listen to you. We are very satisfied and thankful, that we came to this country because we were always treated with respect. $(6 ; 3: 18)$

Simple and routine practices were acknowledged as good practice such as the physician coming to the room of the patient and not vice versa. Caregivers recalled that the physician helped undress the patient or approached the child in an appropriate and friendly way. One caregiver appreciated that the nurse was playing with the child during the consultation. This allowed her to concentrate on the treating physician's explanations. A caregiver from Iraq appreciated that the staff directly addressed the 8-year-old daughter and therefore respected the child's opinion. A further caregiver appreciated that the staff adapted to the individual reactions of the children.

What I liked: my children had two different behaviors. One cried and refused to cooperate. The nurse helped us. [...] We helped each other. By the end both children received what they needed. $(2 ; 11: 10)$

\section{Building trust through relationship}

A trustful relationship to healthcare providers was central to all caregivers when evaluating the quality of healthcare. Two caregivers of children with chronic diseases visited the hospital frequently and described a family-like relationship with the hospital staff.

If I go [to the Children's hospital] I don't see it like a hospital. The nurses, the doctors and everything, they are like my family. $(4 ; 2: 90)$

As verbal communication was frequently limited, non-verbal communication was important for building a trustful relationship. Two caregivers explicitly highlighted how they appreciated when the medical staff was smiling.

If somebody smiles at me, a beautiful smile, that makes me really happy. Then I get a very beautiful feeling. And the doctor was nothing but happy and friendly and smiled all the time at me. $(9 ; 14: 52)$

A trustful caregiver-provider relationship allowed caregivers to accept unfamiliar health concepts. For example, one caregiver was upset about not receiving a prescription for her child, but she explained how this changed after a medical consultation at the emergency department.

I thought she would get a lot of medication, as she had fever. But no: they only gave this suppository to her. [...] They said: don't be frightened, your daughter will be fine. She just needs time to recover. And that was the right way. I went back, and that was right. So that is an ideal doctor to me: Who knows exactly what happens, without giving too many drugs. (10; $7: 40)$

Another caregiver had the concept that she should never leave her infant alone in hospital. Her daughter was admitted with a chronic disease and the medical staff recommended that she go home to rest while her infant remained admitted.

It was a shock. We [...] don't have this in our culture that mum leaves the baby. But later, I said it's very helpful to go out, really because the nurses were $[\ldots]$ very, very good. Then I understood that: If I'm good, she will be good. [...] [...] We have to know that. That the doctor works for us, not against us. (12; $9: 27)$

\section{DISCUSSION}

To our knowledge, this is the first study investigating the perspective of asylum-seeking and refugee caregivers on the quality of healthcare provided to their children in Europe.

The detailed analysis of the interviews displayed a range of challenges for asylum-seeking and refugee caregivers and their sick children. However, despite including a diverse group some universal challenges were noted. This included the development of a trusting relationship, communication including interpreter services and coordination between the healthcare and the asylum systems. These findings confirm results from a recent systematic review which identified communication, continuity of care and confidence as the three main factors influencing healthcare provision to migrants. ${ }^{29}$ However, our study also highlights important additional aspects for this group of patients specifically regarding confidence and continuity of care.

First, confidence was the key factor contributing to satisfaction of the study participants. Confidence was achieved through a trustful caregiver-provider relationship. This finding is also supported by other studies, for example, investigating mental healthcare delivery to migrants. ${ }^{17}{ }^{26}$ In some instances confidence has been described as being an integral part of the treatment. ${ }^{41}$ It is remarkable that small actions such as a smile by the treating physician, being helpful to undress and interacting in a playful way with the sick child were helpful in the process of trust building. This highlights that simple and easy measures may have important benefits for the health of asylum-seeking and refugee children and such 
knowledge needs to be included in transcultural training of healthcare workers.

Second, caregivers explained that challenges regarding the continuity of care were occurring at the intersection of the medical and the asylum-seeking systems. Challenges included the asylum process itself, transport and access to money. Our study identified that for a positive perception of healthcare delivery, these areas required optimal coordination. This result is also echoed in a recent publication describing healthcare delivery models for refugees, which suggested including specialised case managers as one option to improve cooperation between services. ${ }^{42}$ Connecting services may be facilitated by other interventions such as involvement of social workers and predefined referral pathways and specialised migrant health teams.

Third, communication is important in all healthcare encounters and has been identified as a key barrier or facilitator in this study. Numerous earlier studies have investigated the negative influence of language barriers on patient experience, health literacy and patient-provider relationship. ${ }^{43}$ Communication was also described as essential for the adoption of new health concepts, for example, the rational use of antibiotics. ${ }^{44}$ Although the requirement of interpreters is not debated, most healthcare systems in Europe do not have established payment policies for interpreter services. This results in frequent use of ad hoc non-professional interpreters, which is associated with considerable risk of translation errors leading to clinical consequences. ${ }^{45}$ It is therefore important that coverage for interpreter services is included in healthcare insurance plans, which is currently advocated by a position paper published by the Swiss Hospital for Equity network (https://www.hospitals4equity.ch/).

Generally, the caregivers expressed very positive feelings about the medical care their children had received. Nearly all caregivers expressed their gratitude by giving detailed examples of individual support, fast and adequate medical care and a respectful and trustworthy approach by healthcare providers. A recently published study explored expressions of gratitude in women with migrant background whose health needs were not or only partially met and raised questions in how far this speaks to current normative expectations and attempts to restrict welfare. Gratitude might thus be expressed in order to 'avoid being identified as excessively needy, undeserving newcomers. ${ }^{46}$ It is important to take such logics and power relations into account, yet, in our study, none of the participants perceived a failure of the specific hospital or healthcare system. In one case, a person expressed gratitude regarding the overall care, even though she was not satisfied with one of the consultations. This could be part of the general expectations and discourse of gratitude, yet, we also interpret it as a differentiated picture of judging different parts of the same healthcare facility differently.

There is a possibility that through selection bias only satisfied caregivers had agreed to participate in this study. However, only one caregiver meeting the inclusion criteria refused to take part in the study. The approached caregivers were keen to be interviewed and appreciated the opportunity to express their opinion. In contrast, the hospital's earlier efforts to assess patient's satisfaction in asylum-seeking and refugee families using translated satisfaction questionnaires had a low response rate. This suggests that patient satisfaction inquiries using interviews instead of questionnaires are more acceptable to asylum-seeking and refugee caregivers.

A potential limitation of the study is the small number of interviews performed. However, the interviews were rich in content and included a diverse study population regarding cultural and social background, years of residence in Switzerland and reasons for seeking care. The information gathered started to repeat after 11 interviews, signalling saturation regarding the major themes. Nevertheless, we acknowledge that minor aspects might not have been sufficiently covered, or that other participants from different contexts may have differing views. The strengths of this study are the inclusion of a cross-language concept, a solid theoretic background, a thoroughly validated interview guide and the rigorous analysis, supported by an interdisciplinary research team. Therefore, we believe that our findings are relevant to health services in many host countries caring for asylumseeking and refugee families from various backgrounds.

\section{CONCLUSION}

A mismatch of personal competencies and external challenges importantly influences the caregiver-provider relationship. To overcome this mismatch establishment of confidence was identified as a key factor. This can be achieved by availability of interpreter services, sufficient consultation time and transcultural trainings for healthcare workers. Coordination between the family, the asylum and the medical system is additionally required to facilitate this process.

Acknowledgements We thank the participating families for taking part in the study and providing feedback. We thank the team at the asylum reception centre in Basel, including Edna Baumgartner-Guggisberg, Patricia Drai and Ulrike Leutwyler and the coaches Maggie Daems and Sharon Cheva for their cooperation. We thank Doris Herter and the team of HEKS interpreters for an excellent service. We thank Verena Riedo for reviewing the interview guideline. We thank the administration of the outpatient clinic and the emergency department for their support in the recruitment. We thank Kristine Onarheim and Emma Preston for providing feedback on the manuscript.

Contributors $\mathrm{JB}$ and NR were involved in study conception. JB was involved in data acquisition. JB, KS, CDL and NR were involved in data analysis. JB wrote the first draft. JB, KS, CDL, FNJ, BP and NR revised the manuscript. All authors had access to the data and gave intellectual input. JB and NR affirmed that this manuscript is an honest, accurate and transparent report of the results and that no important aspects have been omitted.

Funding This work was supported by the UKBB Foundation. JB was funded by the Botnar Foundation.

Disclaimer The content is solely the responsibility of the authors and does not represent the official views of the funding bodies, which had no role in the design and conduct of the study; the collection, management, analysis and interpretation of the data; or the preparation, review or approval of the manuscript. 
Competing interests None declared.

Patient consent for publication Not required.

Ethics approval As quality control project, this research project does not fall under the remit of the cantonal or federal law of the Human Research Act (HRA). The Ethikkommission Nordwest- und Zentralschweiz (EKNZ) has reviewed the submitted documents and confirms that the research project fulfils the general ethical and scientific standards for research with humans (see Art 51 Abs 2 HRA).

Provenance and peer review Not commissioned; externally peer reviewed. Data availability statement № additional data are available.

Open access This is an open access article distributed in accordance with the Creative Commons Attribution Non Commercial (CC BY-NC 4.0) license, which permits others to distribute, remix, adapt, build upon this work non-commercially, and license their derivative works on different terms, provided the original work is properly cited, appropriate credit is given, any changes made indicated, and the use is non-commercial. See: http://creativecommons.org/licenses/by-nc/4.0/.

\section{REFERENCES}

1. UNHCR. global trends - forced displacement in 2017. 72. UNHCR, 2017.

2. UNICEF. Latest statistics and graphics on refugee and migrant children. secondary latest statistics and graphics on refugee and migrant children 26 December 2017, 2018. Available: https://www. unicef.org/eca/what-we-do/emergencies/latest-statistics-andgraphics-refugee-and-migrant-children

3. UNICEF. Refugee and migrant crisis in Europe. humanitarian situation report \# 29. secondary refugee and migrant crisis in Europe. humanitarian situation report \# 29, 2018. Available: https://www. unicef.org/eca/sites/unicef.org.eca/files/2018-10/Refugee\%20and\% 20Migrant\%20Crisis\%20in\%20Europe\%20Situation\%20Report\% 20No.\%2029\%20July\%20-\%20Sep\%202018 0.pdf

4. Migration SSo. Asylstatistik 2017. secondary Asylstatistik 2017, 2017. Available: https://www.sem.admin.ch/dam/data/sem/ publiservice/statistik/asylstatistik/2017/stat-jahr-2017-kommentar-d. pdf

5. Eurostat. Asylum statistics secondary asylum statistics, 2018 Available: https://ec.europa.eu/eurostat/statistics-explained/index. php/Asylum_statistics\#Age_and_gender_of_first-time_applicants

6. Malmusi D. Immigrants' health and health inequality by type of integration policies in European countries. Eur J Public Health 2015;25:293-9.

7. Marquardt L, Krämer A, Fischer F, et al. Health status and disease burden of unaccompanied asylum-seeking adolescents in Bielefeld, Germany: cross-sectional pilot study. Trop Med Int Health 2016;21:210-8.

8. Ritz N, Brinkmann F, Garcia BS, et al. Tuberculosis in young refugees. The Lancet 2015;386:2475-6.

9. Pohl C, Mack I, Schmitz T, et al. The spectrum of care for pediatric refugees and asylum seekers at a tertiary health care facility in Switzerland in 2015. Eur J Pediatr 2017;176:1681-7.

10. The Lancet. Migrant and refugee children need our actions now. The Lancet 2016;388.

11. Baauw A, Ritz N. Towards better healthcare for migrant and refugee children in Europe. Eur J Pediatr 2018;177:161-2.

12. Koller TS. Beyond the barriers. WHO, 2017.

13. Jaeger FN, Hossain M, Kiss L, et al. The health of migrant children in Switzerland. Int J Public Health 2012;57:659-71.

14. MacFarlane A, Ryan S. Do we all agree what "good health care" looks like? Views from those who are "seldom heard" in health research, policy and service improvement. Int J Equity Health 2017;20:878-85.

15. Madden $\mathrm{H}$, Harris J, Blickem $\mathrm{C}$, et al. "Always paracetamol, they give them paracetamol for everything": a qualitative study examining Eastern European migrants' experiences of the UK health service. BMC Health Serv Res 2017;17:604.

16. Robertshaw L, Dhesi S, Jones LL. Challenges and facilitators for health professionals providing primary healthcare for refugees and asylum seekers in high-income countries: a systematic review and thematic synthesis of qualitative research. BMJ Open 2017;7:e015981.

17. Blignault I, Ponzio V, Rong Y, et al. A qualitative study of barriers to mental health services utilisation among migrants from mainland China in south-east Sydney. Int J Soc Psychiatry 2008;54:180-90.

18. Chen YYB, Li AT-W, Fung KP-L, et al. Improving access to mental health services for Racialized immigrants, refugees, and Non-Status people living with HIV/AIDS. J Health Care Poor Underserved 2015;26:505-18.

19. Deeb-Sossa N, Díaz Olavarrieta C, Juárez-Ramírez C, et al. [Experiences of undocumented Mexican migrant women when accessing sexual and reproductive health services in California, USA a case study]. Cad Saude Publica 2013;29:981-91.

20. Espinoza R, Martínez I, Levin M, et al. Cultural perceptions and negotiations surrounding sexual and reproductive health among migrant and non-migrant Indigenous Mexican women from Yucatán, Mexico. J Immigr Minor Health 2014;16:356-64.

21. Fazel M, Garcia J, Stein A. The right location? experiences of refugee adolescents seen by school-based mental health services. Clin Child Psychol Psychiatry 2016;21:368-80.

22. Nadeau L, Jaimes $A$, Johnson-Lafleur J, et al. Perspectives of migrant youth, parents and clinicians on community-based mental health services: negotiating safe pathways. J Child Fam Stud 2017;26:1936-48.

23. Newton AM. The health beliefs of migrant Farmworker parents: an ethnographic exploration. J Immigr Minor Health 2016;18:582-8.

24. Riggs E, Davis E, Gibbs L, et al. Accessing maternal and child health services in Melbourne, Australia: reflections from refugee families and service providers. BMC Health Serv Res 2012;12.

25. Valibhoy MC, Kaplan I, Szwarc J. "It comes down to just how human someone can be": A qualitative study with young people from refugee backgrounds about their experiences of Australian mental health services. Transcult Psychiatry 2017;54:23-45.

26. Van Son CR, Gileff TY. Relying on what they know: older Slavic emigres managing chronic health conditions. Qual Health Res 2013;23:1660-71.

27. Worabo HJ, Hsueh K-H, Yakimo R, et al. Understanding Refugees' Perceptions of Health Care in the United States. The Journal for Nurse Practitioners 2016;12:487-94.

28. Yelland J, Riggs E, Wahidi S, et al. How do Australian maternity and early childhood health services identify and respond to the settlement experience and social context of refugee background families? BMC Pregnancy Childbirth 2014;14.

29. Brandenberger J, Tylleskär T, Sontag K, et al. A systematic literature review of reported challenges in health care delivery to migrants and refugees in high-income countries - the $3 \mathrm{C}$ model. BMC Public Health 2019;19:755.

30. Condon LJ, McClean S. Maintaining pre-school children's health and wellbeing in the UK: a qualitative study of the views of migrant parents. J Public Health 2017;39:455-63.

31. State Secretary of Migration. Empfangs und Verfahrenszentren. secondary Empfangs und Verfahrenszentren 01.07.2017, 2017. Available: https://www.sem.admin.ch/sem/de/home/asyl/ asylverfahren/empfang/uebersicht evz.html

32. Sarah Elsie baker MurE, NCRM, University of Southampton. How many qualitative interviews is enough?. 26.03. National center for research methods, 2012. Available: http://eprints.ncrm.ac.uk/2273/

33. Saunders B, Sim J, Kingstone T, et al. Saturation in qualitative research: exploring its conceptualization and operationalization. Qual Quant 2018;52:1893-907.

34. Agee J. Developing qualitative research questions: a reflective process. International Journal of Qualitative Studies in Education 2009;22:431-47.

35. Squires A. Methodological challenges in cross-language qualitative research: a research review. Int J Nurs Stud 2009;46:277-87.

36. Wallin A-M, Ahlström G. Cross-Cultural interview studies using interpreters: systematic literature review. J Adv Nurs 2006;55:723-35.

37. Al-Amer R, Ramjan L, Glew P, et al. Language translation challenges with Arabic speakers participating in qualitative research studies. Int J Nurs Stud 2016;54:150-7.

38. G. L. Dolmetscher/inneneinsatz in der qualitativen Sozialforschung Zu Anforderungen und Auswirkungen in gedolmetschten Interviews. Forum: qualitative Sozialforschung - social research; 2014.

39. Mayring P. Qualitative content analysis: theoretical foundation, basic procedures and software solution. Klagenfurt: Social Science Oppen Access Repository, 2014.

40. Tong A, Sainsbury P, Craig J. Consolidated criteria for reporting qualitative research (COREQ): a 32-item checklist for interviews and focus groups. Int J Qual Health Care 2007;19:349-57.

41. Benson J, Haris TA, Saaid B. The meaning and the story: reflecting on a refugee's experiences of mental health services in Australia. Ment Health Fam Med 2010;7:3-8

42. Joshi C, Russell G, Cheng I-H, et al. A narrative synthesis of the impact of primary health care delivery models for refugees in resettlement countries on access, quality and coordination. Int J Equity Health 2013;12:88. 
43. Yeheskel A, Rawal S. Exploring the 'Patient Experience' of Individuals with Limited English Proficiency: A Scoping Review. J Immigr Minor Health 2018.

44. Lindenmeyer A, Redwood S, Griffith L, et al. Recent migrants perspectives on antibiotic use and prescribing in primary care: a qualitative study. Br J Gen Pract 2016;66:e802-9.
45. Flores G, Laws MB, Mayo SJ, et al. Errors in medical interpretation and their potential clinical consequences in pediatric encounters. Pediatrics 2003;111:6-14.

46. Bradby $\mathrm{H}$, Humphris R, Padilla B. Universalism, diversity and norms: gratitude, healthcare and welfare chauvinism. Crit Public Health 2018;11:1-13. 